\title{
Trauma care in England and Wales: Is this as good as it gets?
}

\section{F E Lecky}

\section{Outcome has plateaued since 1994 but varies significantly at Trust level}

T his edition publishes an analysis from the TARN database suggesting that the case mix fatality for major trauma patients reaching hospital alive has not improved in England and Wales since 1994 even though a $40 \%$ reduction occurred in the preceding five years (1989-94). This lack of change in outcome occurred in parallel with a plateau in the level of consultant involvement in the most severely injured patients. ${ }^{1}$ Two important issues arise from this observational study. The first concerns the validity of the analysis and the second if the analysis is valid, the response of emergency physicians.

The TARN sensitivity analysis has adjusted the observed lack of change in outcome for most potential weaknesses in the data, this did not change the main results. Furthermore, there are very few if any data in international literature that have commented in trends in trauma outcome after 1995 therefore it is possible that this plateau in case mix fatality is not just a trend in England and Wales but one that extends throughout the developed world. The implementation of evidence based medicine may secure further improvements, however, this is not straightforward. There is little class one evidence to support care for major trauma patients in the emergency department. Two randomised control trials spring to mind: the first from Houston that suggests $4 \%$ to $8 \%$ excess mortality in shocked patients with penetrating trauma being fluid resuscitated (compared with no fluid resuscitation) before surgery, ${ }^{2}$ the second being the NASCIS study suggesting benefit in terms of functional outcome for patients with spinal cord injury given high dose corticosteroids within eight hours. ${ }^{3}$ Further reviews of emergency department interventions on the Cochrane injuries database have been inconclusive. ${ }^{45}$ Moving away from single interventions there are data from North America that suggest that organised trauma systems are beneficial in terms of reducing mortality. ${ }^{6}$ However, even in North America this is not generally accepted. Within the United Kingdom two studies of trauma care systems have not suggested benefit for the trauma populations studied. ${ }^{89}$

With little in the way of firm evidence to guide practice one must look to researchers to try and improve the evidence based. However, this is a difficult area. There are complex ethical issues surrounding the recruitment of patients who are not fully conscious into randomised controlled trials. Trials inevitably have to be large and multicentre as although major trauma remains the commonest cause of death in young people it is still a sporadic disease in individual emergency departments. Multicentre trials require significant investment and as emergency physicians rarely own the whole of a major trauma patient for longer than a few hours, efforts to collaborate with orthopaedic and neurosurgical colleagues (who will be responsible for the ongoing care of most of these patients) are also necessary. It is therefore difficult for emergency physicians to initiate trials to answer questions such as the time frame within which it is acceptable to deliver operative intervention for specific injuries. This makes it unlikely that many large multicentre trials will deliver the answer to therapeutic dilemmas within the next five years. Large trauma registries may be able to provide some comparatively high quality observational evidence, however, most rely on mortality rather than disability outcomes. The mortality for major trauma patients reaching hospital alive is low, between $5 \%$ and $10 \%$ in most registries on both sides of the Atlantic, ${ }^{10}$ (perhaps a reflection of improvements in care before the mid-1990s). Therefore the ability of trauma registries to determine the efficacy of single therapeutic interventions is limited by considerations of power. The data presented in this journal do show however that although nationally outcome is static, there is a large degree of variation in outcome between different hospitals suggesting that some deliver better trauma care than others. ${ }^{1}$ For the reasons discussed it is less than clear what the key features in improving outcomes are.
To continue to move forward action is probably needed at a number of levels. A resurgence of government interest in reducing injury morbidity would provide valuable leadership and help in delivering resources to tackle the research agenda. Although injury prevention initiatives should always be pursued it is probable that the consequences of road traffic crashes will provide challenges for emergency physicians in the foreseeable future. ${ }^{11}$ While we try and move forward it is also important that we do not slip back; maintaining the current level of consultant involvement in major trauma and of ATLS training is probably important in preserving the status quo. ${ }^{1}$

For emergency physicians moving forward will mean determining whether we are happy to participate in trials randomising patients unable to give consent outwith of a national debate surrounding ethical issues (similar to that which took place in the United States before FDA approval of informed consent waivers after local community consultation). Alongside surgical and anaesthetic colleagues we will need to determine which interventions require further study and which disability based outcome scale becomes standard. ${ }^{12-14}$ It may even be worth pursuing a more radical before/ after trauma system experiment, which to some degree was advocated by the most recent Royal College of Surgeons/ British Orthopaedic Association report. ${ }^{15}$ Evidence from observational databases may be useful for plotting epidemiological trends in trauma outcome and process. However, while these are focused upon mortality the potential for even high quality observational data to test the efficacy of trauma interventions will be limited. Progress in these areas is possible but challenging. Turning away from the challenge may well mean that for best performing English and Welsh hospitals current trauma care is as good as it gets.

Emerg Med J 2002;19:488-489

\section{Author's affiliations}

F E Lecky, University of Manchester, Eccles Old Road, Salford M6 8HD, UK

Correspondence to: Dr F E Lecky;

flecky@fs 1.ho.man.ac.uk

\section{REFERENCES}

1 Lecky FE, Woodford M, Bouamra O, et al. Lack of change in trauma care in England and Wales since 1994. Emerg Med J 2002;19:520-4.

2 Bickell WH, Wall Jr M, Pepe P, et al. Immediate versus delayed fluid resuscitation for hypotensive patients with penetrating tors injuries. N Engl J Med 1994;331:1105-9.

3 Bracken MB, Shephard M, Collins WF, et al. A randomised controlled trial of methylprednisolone in the treatment of acute spinal cord injury. N Engl J Med 1990;332:1405-11.

4 Cochrane Injuries Group Albumin

Reviewers. Human albumin administration in 
critically ill patients; systematic review of randomised control trials. BM

1998;317:235-40

5 Alderson P, Roberts I. Corticosteroids in acute traumatic brain injury: systematic review of randomised controlled trials. BM 1997;314:1855-9.

6 Jurkovich GJ, Mock C. Systematic review of trauma system effectiveness based on registry comparisons. J Trauma 1999;47/suppl 3): $446-55$.

7 MacKenzie EJ. Review of evidence regarding trauma system effectiveness resulting from panel studies. J Trauma 1999;47 (suppl 3):S34-41.
8 Nicholl JP, Brazier JE, Snooks HA. Effect of London helicopter emergency service on survival after trauma. BM 1995;311:21722.

9 Yates DW. Regional trauma systems. BM 1997:315:1321.

10 Copes WS, Staz CF, Konvolinka CW, et al. American College of Surgeons audit filters: associations with patient outcome and resource utilisation. J Trauma 1995;38:432-8.

11 Roberts I, Mohan D, Abbasi K. War on the roads. BM 2002;324:1 107-8.

12 Wilson JT, Petegrew LE, Teasdale GM. Structured interviews for the Glasgow
Outcome Scale and the Extended Outcome Scale. J Neurotrauma 1998;15:573-85.

13 Euroqual group. Euroqua-a new facility for health related quality of life. Health Policy 1990; 16:199-208

14 Mackenzie E. Physical impairment and functional outcome six months after severe lower extremity fractures. J Trauma 1993;34:528-39.

15 Royal College of Surgeons of England and British Orthopaedic Association. A Joint Report from The Royal College of Surgeons of England and the British Orthopaedic Association. Better care for the severely injured. London: 2000. 